\title{
Editorial note to the coordinators' reports
}

\author{
ANTHONY BLADON
}

The Kiel Convention for revising the alphabet of the IPA (see Ladefoged and Roach 1986) provides for working groups whose coordinators have begun to collate preliminary comments from among those who responded to the conference preregistration. Many of the group coordinators have submitted their respondents' comments to the Journal, and some are reprinted here (with slight editing in some cases). Members planning to attend the Kiel Convention will wish to have briefed themselves on these submissions before attending.

The Editor is very grateful to other coordinators (Elizabeth Uldall and Arne Foldvik) who submitted notes and letters which are not published here.

Readers who wish to do so may still continue to submit comments to the coordinators (whose names are listed in this issue on pp. 62-4). Let us emphasize once again that we welcome a wide constituency of views, from any users of the Association's alphabet, whether they are phoneticians or not.

\section{References}

LADEFOGED, P. and P. ROACH (1986). Revising the International Phonetic Alphabet: A plan. Journal of the International Phonetic Association 16, 22-9. 